\title{
EVALUACIÓN DE LA CALIDAD NUTRICIONAL Y MORFOLOGÍA DEL GRANO DE VARIEDADES AMARGAS DE QUINUA BENEFICIADAS EN SECO, MEDIANTE EL NOVEDOSO EMPLEO DE UN REACTOR DE LECHO FLUIDIZADO DE TIPO SURTIDOR
}

\author{
Carla Quiroga Ledezma y Ramiro Escalera Vásquez
}

\section{RESUMEN}

La tecnología desarrollada para el beneficiado de variedades amargas de quinua en seco tiene per se varios beneficios respecto a las ofertas tecnológicas actuales: ahorro en el consumo de agua y recursos no renovables (gas), la no generación de efluentes contaminados con saponinas y la recuperación total de las saponinas. En este trabajo se evaluó la calidad de la quinua beneficiada, para ello, se realizaron pruebas experimentales en los equipos de laboratorio y prototipo piloto con 3 ecotipos de Quinua Real (Blanca, Amarilla y Rosada) de las zonas de Garci Mendoza y Uyuni. Muestras de quinua fueron procesadas de acuerdo a un diseño experimental, evaluándose el efecto de las variables: ecotipo, diámetro de reactor, diámetro de boquilla y altura de lecho en el porcentaje de remoción de saponinas, la calidad nutritiva (porcentaje de proteína y materia grasa) y cambios en la morfología del grano procesado.

Los resultados muestran claramente que los factores preponderantes en la remoción de saponinas son el diámetro de reactor, el diámetro de la boquilla, seguido del ecotipo. Las condiciones óptimas de procesamiento se dan en los intervalos de 1,4 a $1,8 \mathrm{~mm}$ para el diámetro de boquilla y 7,5 a $12,5 \mathrm{~cm}$ para el diámetro de reactor y una altura de lecho de $12,5 \mathrm{~cm}$, en estos intervalos los niveles del contenido de saponina en el grano están entre 0 y $0,02 \%$, niveles muy por debajo de lo que establece la Norma Boliviana NB NA $0038(<0,12 \%)$. La calidad nutritiva de la quinua no sufre ningún deterioro, los porcentajes de proteína y materia grasa están por encima de los niveles mínimos establecidos en la norma anteriormente mencionada, $>10 \%$ y $>4 \%$ respectivamente, y tampoco hay signos de daños en la superficie de la microestructura del grano.

Por tanto, se puede concluir que la quinua beneficiada en el reactor de lecho fluidizado de tipo surtidor tiene una calidad igual o mejor a la quinua que ha sido escarificada, lavada y secada durante el beneficiado.

Evaluación de la calidad nutricional y morfología del grano de variedades amargas de quinua beneficiadas en seco, mediante el novedoso empleo de un reactor de lecho fluidizado de tipo surtidor

Palabras Clave: Quinua, Saponinas, Desaponificación, Reactor de Lecho Fluidizado de Tipo Surtidor. 